und veraltet, so soll man sie wegwerfen und durch neue ersetzen. Nur wenn die dazu Berufenen sich dieser Pflicht bewußt bleiben, mit der Zeit zu gehen und wo es möglich ist, ihr vorans zu eilen, arbeiten sie in Sinne der großen Meister des Corpus, im Sinne von Boeckh und jetzt noch mehr in dem des Größten von allen, der ganz Römer war und sein wollte und der dnch auch uns Griechen unendlich viel gelehrt hat, von Theodor Mommsen. ${ }^{\text {) }}$

[Berlin im Juli 1904.]

\title{
Feuerpost.
}

Von Siegmund Fraenkel.

Im Anschluß an die in diesen Beiträgen (III 169, IV 117) gesammelten Nachrichten ist vielleicht auch ein Hinweis auf einen Bericht der Mischnah interessant, in der von der Einrichtung einer Feuerpost die Rede ist. Rôš Hašânâh II 2 ff. wird Folgendes überliefeıt: „Früher zündete man (um in zweifelhaften Fällen den Eintritt des Neumonds den auBerhalh Jerusalens und in Babylonien wolnenden Juden zu melden) Bergfeuer an .... Man nahm lange Stangen aus Cedernholz, an die man mittelst eines Fadens (an der Spitze) Rolır, Olivenholzstücke und Werg befestigte. Dann entziindete man sie auf der Spitze eines Berges und bewegte sie nach allen Seiten, so lange, bis man clas nächste Feuer auf dem zweiten, dritten Berge usw. sall. Wo begann das Anzünden der Fackeln? Auf dem Ölberge. Von da aus (ging die Verbindung) nach Sartaba, von Sartaba nach Agrippina, von da nach Chauran, von da nach Betlı Baltın" usw.

\section{Keilinschriftliches zur Sphärenmusik?}

\section{Von C. F. Lelımann.}

Der ron mir vor Jahren veröffentlichte Text, ${ }^{2}$ ) der nenerdings den ersten Anstob gab zur Ermittelung der Feuerpost als einer Einrichtung, die sich von Babylonien aus äber die antike Kulturwelt verlsreitet hat, birgt auscheinend noch ein weiteres, nicht minder wichtiges Zeugnis für Vorstellungen, die man bei den Babyloniern längst vermuten mußte, ohne sie doch bisiner nachweiseu zu können.

Der Gott Marduk, aus Babylon von Sanherib entführt, wird von dessen Enkeln Assurbanabal und Šamaššumukìn, ${ }^{3}$ ) von Assur nach Babylon zurück-

1) In Mommsens und auch schon in Niebuhrs sinne werden von jetzt ab in den griechischen Corpora auch die lateinischen und barbarischen Inschriften (z. B. für Lemnos die bekannte 'pelasgisch' -sintische) bertïcksichtigt werdeu. Für Kleinasien ist auch dieses Prinzip schon anerkannt und eingeführt worden.

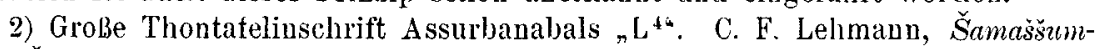
ukîn [ک̌amašs.], König von Babylonien etc. (Assyriol. Bibliothek Bd. VIII 189\%) Teil I S. $27 \mathrm{f}$. sub. 13, 'Teil II S. 63-71 Tafel XXXIV-XXXIX.

3) Über das Verhältnis der beiden Brüder zu ihrem Vater Assarhaddon erhalten wir durch einen von Meißner Assyriol. Studien II, Mitteil. d. corderas. Ges. IX (1904) Nr. 3 S. 181-184 [l-4] vor kurzem ins rechte Licht gesetzten Text weitere Aufschlüsse, durch welche die lange Reihe von Bestätigungen, die sich für meine aus den 1892 vorliegenden Inschriften gezogenen Schlußfolgerungen (Šamašs. Teil I Kap. III) ergeben haben, eine weitere Bereichlerung erfährt. Aber Šamaššumukîn heißt - gegen Meißner - ablu rabû nicht als älterer Bruder Assurbanabals. 